\title{
Towards Assessment of information system agility
}

\author{
Fatima Zohra TANANE \\ Université de Lyon, Univ. Lumière Lyon 2, DISP Lab EA4570, \\ Email: fatima.tanane@insa-lyon.fr \\ Vincent CHEUTET \\ Université de Lyon, INSA Lyon, DISP Lab EA4570 \\ Email: vincent.cheutet@insa-lyon.fr
}

Jannik LAVAL

Université de Lyon, Univ. Lumière Lyon 2, DISP Lab EA4570,

Email: jannik.laval@univ-lyon2.fr

\begin{abstract}
Currently, the information systems agility and the satisfaction of the dynamic environment requirements is essential challenges for companies. The purpose of this paper is to represent the existing approaches for achieving agility in software development as well as in production system. The objective is to identify the relevant metrics for evaluating information system agility. Then, we propose an analysis model that contains these agile metrics, to observe their combination in information system.
\end{abstract}

\section{INTRODUCTION}

The information system is dealing with the dynamic structure of the environment, which appeals the concept of agility. In 2012, the Standish group [1] shows that the percentage of failure project using agile method is minimal than the ones working with traditional methods such as waterfall method [2]. Thought, the use of traditional methods represents more challenges. It aims to meet the primarily traced objectives and respect well defined contractual schedule. Consequently, the use of such traditional methods limits creativity and profitability by becoming a prisoner of contract. Otherwise, the absence of communication with the customer leads easily to fall into the trap of "tunnel effect" [3]. Another solution is the use of adaptive systems and many other different architectural approaches [4]. However, these methods are not built on flexibility but on the reliability and robustness over time. For all these reasons, agility remains the most important approach for information system.

The issue continues to arise concerning the agility meaning. In order to define information system agility, we must pass through production system and the software development agility. On one hand, production systems must achieve one level of agility. The customer is now requiring the best products, at the best price and in less time, but also with more customization. It obliges the companies to be more open and accept the possibility of changes at any stage of the project. Hence, different supply chain models are dedicated to measure the agility performance [5] or through the complexity of the environment [6]. On the other hand, in software development, we find agile methods as Scrum [7] and Extreme Programming (XP) [8] that continue to draw attention of businesses.

The experience shows that agility which determines the two worlds of production system and software development is lost by using them together in the information system. For example, while using an Enterprise resources planning (ERP) to manage business processes. Indeed, despite the agility supposed to be acquired, the system becomes unable to cover the business needs requested and the dysfunction takes over. Thus, we can say that the information system agility is the combination of the agility in those two domains. The problem that arises is how to define information system agility which let to measure the level of agility and control it.

This paper is structured as follows: section 2 introduces the state of the art of agility in production systems and in software development. We finish this section by a definition of information system agility. Section 3 presents existing metrics for analyzing agility of a system. Then, section 4 describes a model to measure the capability of an information system agility. Finally, we conclude this paper in section 5.

\section{PARAdigm OF Agility}

\section{A. Agility state-of-art}

The first definition was given by Conway in 1968. He said: "Any organization that designs a system will inevitably produce a design whose structure is a copy of the organization's communication structure" [9]. Rather late, this result was well supported by scientific.

Since we are in the supply chain while using an information system tools, it seems obvious to evoke the agility in production systems. Kidd [11] in his book "Agile Manufacturing" define agility as a timely and proactive adaptation of business elements to unexpected changes that can't be anticipated. He proposes a conceptual framework for agility. For Golldman et al [12] agility is a kind of complete response to the confrontation, obligated by a business environment, overpowered by change and doubt. Gunasekaran [13] define the Agile Manufacturing (AM) as the capacity to continue to live and succeed in a competitive environment undergoing a continuous and unpredictable changes. Manufacturing Agility consists to have a rapid time response and adaptation to market changes, based on customer choices. According to Yusuf et al [14] agility means to win to implement a competitive metric, in order to be quick, flexible and creative. For Yusuf, the agility purpose is to know how to integrate reconfigurable resources and best practices, to assure a good quality and to provide 
products and services for the customers because agility is the fact to be adapted to a rapid environment changes.

In managerial context, the "Lacocca" Institute defines agility as "manufacturing system with the capacity to meet the rapidly changing needs of the market" [15]. According to Shaw et al [16] agility is considered as the levels of the virtualization of the organization with a strategic choice of partners and supported by e-commerce.

Those definitions despite their differences, it treats common characteristics of agility; flexibility and the adaptation to the unpredictability of the environment.

In software development, agility is based on four values and twelve principles, written by several experts of software engineering. The four values emphasize "individuals and interactions over processes and tools, operational software over comprehensive documentation, customer collaboration over contract negotiation, adaptation to change more than monitoring a plan" [10]. According to the Alliance association, to be agile is: "An umbrella term for a set of methods and practices, based on the values and principles. [..] Solutions evolve through collaboration between self-organizing, crossfunctional teams, utilizing the appropriate practices for their context".

According to the 9th Annual state of agile survey, Scrum takes over and used by 56 percent of the company, while other methods are behind scrum with little use (1).

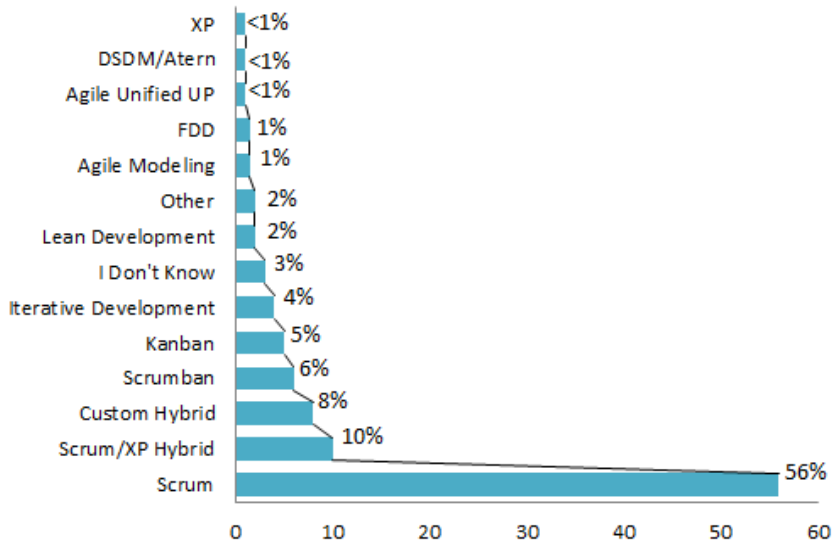

Fig. 1: Agile methodology used by business [17]

\section{B. Synthesis}

These proposed definitions of agility are not complete but rather complementary. Indeed, the information system is a mixture of software layers and high level layers related to the business entity. Hence, we must jointly conduct two types of approach. Initially, the first one will be based on the definition of agility in production systems, then in the software development, in order to see their combination in information systems. For example, this problem arises when we combine an agile production system with an information system tool as an ERP which is developed in a completely agile way. The question that can be asked is if this combination is naturally agile or it must validate other criteria to let the system to meet the business requirement behind it.

\section{Defining Information System Agility}

In order to define the information System agility, we must firstly understand the information system architecture and his business tools and their challenges. Thus, by summarizing all these aspects we can offer a complete definition of the information system agility

1) IS Architecture: Le Moigne [18] considers that each organization has three system subsets. The "operational system"; it performs the company's operation, production and use of information. The "control system"; it is dedicated to the leader of the company and the decision takers to make decisions. Finally, the "information system" which is in the middle of these two systems. It is considered as an outlet for the operating system and an input for the control system. It stores the information produced by the "operational system" to allow taking decisions for the "control system".

The work of Goepp [19] added the interpretive aspect to the "instrumentalist view". Then, the role of an information system is not limited to the processing of information but it can also interpret this information and produce individual representation. The purpose is to use appropriate technologies for each team in a sense of exchange and negotiation.

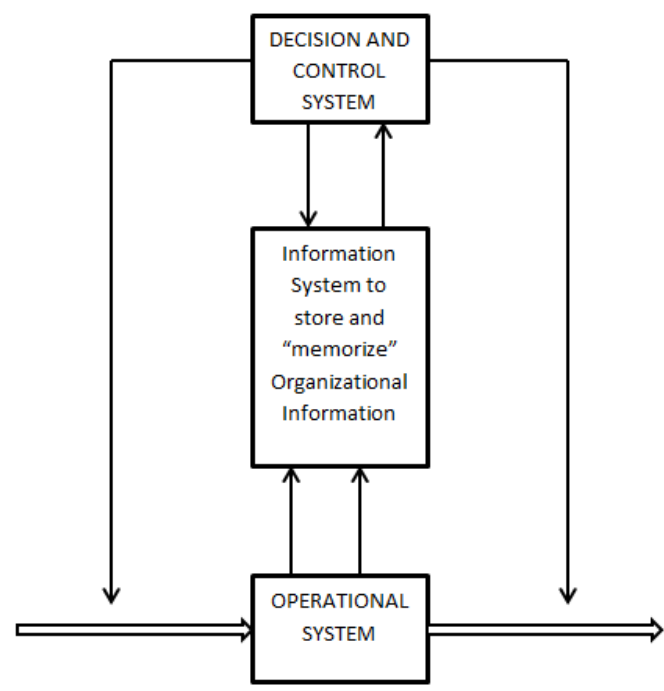

Fig. 2: The Systemic Model of the Organization (Le Moigne 1986)

2) IS Challenges: The Information System Application Software is available in different types. It depends on specific goals. It meets various players in the product development process while design and production.

On one hand, at the production of several systems level, the first industrial management IT tools were focused on production management and appeared in the 60s. Their features were converted to business designated by MIS. 
On the other hand, at the design level, the IS business is the Product Data Management Tool (PDM). According to Eynard [20], a PDM system is operable to manage the data relating to the design and manufacture of products.

Now, different information systems coexist: MES, APS, CRM and ERP. these business tools have different challenges. According to Panorama research 63-percent of companies had trouble in addressing process and organizational change issues [21]. If we take the case of the ERP, we find that it is not flexible. Making changes is more difficult because of the robustness of the source code. This last one is closed and does not allow adding changes on a regular basis. The major reason for the failure in the ERP project is its inability to manage the alignment of the standard features and the real needs. It is due to the differences between deployment and the integration team. Furthermore, there is a constraint about delays which is often overwhelming and make changes neglected. Only 50 per cent of the objectives are achieved which means that the availability of information and improved interaction between the contributors and with customers are not satisfied. To resolve this challenges we should use the concept of alignment and interoperability.

3) The strategic alignment: Henderson and Venkatraman [22] give this definition: "the alignment process refers to an organizational process where the mission goals, objective, and activities of the IS function change over time in parallel with exchange in the organization".

4) Interoperability and semantic: The interoperability of information system participates in the Product Lifecycle Management (PLM). It aims for ensuring the semantic in the complex PLM system. The interoperability definition is given by Paviot [23] as the ability of two systems to exchange and use information. Researches have sought to ensure the business agility during the integration of data that are typically derived from different resources. In this case, the solution is the semantic mediator [24]. It is used as a means for interoperability of information systems, to improve trade and overcome the problem of communication. The semantic mediator centralizes data and avoids semantic conflicts by adding an extra layer to unify dialog.

The information system should not be considered only as a software. Summarizing the different definition of the agility state of art and considering the IS challenges, we can say that:

"The Information System is agile from the moment it appropriates a set of processes and strategies that involves incrementally the user, to acquire the ability to adapt flexibly to the information system changes and continue to achieve goals, by decreasing response time, despite the pressure and the turbulent in the unpredictable environment."

\section{EXISTING METRICS}

\section{A. Metrics definition}

The term metric is widely used in different areas. It generally refers to a unit or a measurement indicator used to judge the effectiveness of an activity. The proliferation of metrics can be explained by measuring the activities and the ongoing emergence of new techniques. Many metrics are used especially in the management, area of development, trade links... The software metric is a compilation of measurements from the technical or functional properties of software [25]. It is possible to classify the software metrics in three categories: application maintenance, application quality and respect for development process.

In the field of software development, the use of standardization is the most popular method of ensuring the agility of the information system. It allows portability of applications, by giving the ability to move between different platforms in a hybrid frame without the need for a full or partial reengineering. To implement this approach, it is necessary to set adaptability metrics. Especially with the arrival of cloud architecture [26] which facilitates the sharing of platform changes. But the concern remains in the interpretation of these standards by the run-time engine.

There is a methodology which proposes, validates and practically evaluates a framework for measuring portability by measuring adaptability [27]. The limit of that kind of approaches is that it merely treats problems related just to the software layer to see deeper. However, for a higher vision of information systems it doesn't offer a comprehensive way models.

Some models calculate agility in its average based on the tendency of the market and analysis of the objectives to identify agility means [28] [29]. These models are based on simple approaches from assessing the current situation and identifying the means and tools to achieve the agility to provide a comprehensive view [30]. However, a quantifiable index is not available and the assessment is based on crisp values which are appropriates to each organization. There are more accurate models that attempt blurred multi-grade approach using a model following the analytic hierarchy process AHP. It can be used to determine possible ways of agility based on the organization's performance proposed by Rent at al. [31].

In the same way, the work of Tsur et al [32] combines the infrastructure with human resources of the organization using the logical (if-then), working with fuzzy number. But this method is complex and suffers from a lack of flexibility with new situations. Yang Lil year [33] calculated agility as the weighted sum of the company's ratings. But, this framework remains specific to the organization using mass customization which is a marketing technique and workmanship that combines flexibility and customization with the low unit costs of mass production "to measure" mass customized (MC).

Indirect methods have also been proposed such as the measurement of the complexity, which is based on its inverse relationship with the agility. It is proposed by Arteta et al. [34]. He shows that in general the most complex projects are the less agile Yauch [35] highlights the turbulence index of the environment, in order to minimize the inaccuracy empirically to have a single output for more accurate result. Although this type of model does not offer improvements in agility. It is conditioned by the mastery of the environment, which is 
a difficult task due to the dynamic aspect of unpredictable environments.

\section{B. Synthesis}

After this general reading of existing metrics, we reinforce the need for agility. Nevertheless, the models proposed are not enough to success. The information system is not only a software but we must also include a high-level vision. We know the approaches of alignment and interoperability of information systems. Now, they must work together to analyze the agility of the information system to improve its performance in uncertain environments.

The literature provides a set of metrics of agility assessment but they are not sufficient. The idea is to use them per each context to propose a model based on the existing metrics but by projecting them on a new structure adapted to the environment.

The analysis of existing references, shows that there are few links between the metrics of software and business process in current approaches.

\section{AgILITY METRICS MODEL}

After this study of the agility definition and the information system challenges, we introduce an analysis model to give a concrete vision at agility reaches by an information system. The proposed model treats and describes a special metrics dedicated to evaluate agility in the information system. It is inspired from the agile definition cited in Section 2. To find answers regarding the agility of information systems, we propose a model that goes around on these aspects.

This is an analysis model comprising metrics for evaluating agility per 2-dimensional. The choice of two dimension came to facilitate the judgment through the metric, because a relationship between two strangers is more relevant than several dimensions at once. Consequently, we choose a square plan which will allow us to visualize the objectives of the metrics. The projection on the plane allows external analysis to observe the relationship with the environment, but also internally observing correlation between these metrics.

We have a first dimension regarding the levels of analysis. The idea is to separate the software part of the business part, in order to located the exact source of agility problems. The second-dimension deals with metrics depending on the situation we want to achieve. Indeed, we assess how our system can adapt to the environment changes. Hence, these metrics leads us to discover what are the steps that must be implemented for the continuity of productivity. It shows how to reduce response time and keeping an eye on customer expectations in order to avoid the "tunnel effect".

Thus, evaluating the agility of an information system will be through the cross between the two dimensions, depending on the situation we want to evaluate. Figure 3 summarizes all the levels for evaluating the agility. Table 1 shows the intersection of the two dimensions. References in the table are explained in Section 4-C.

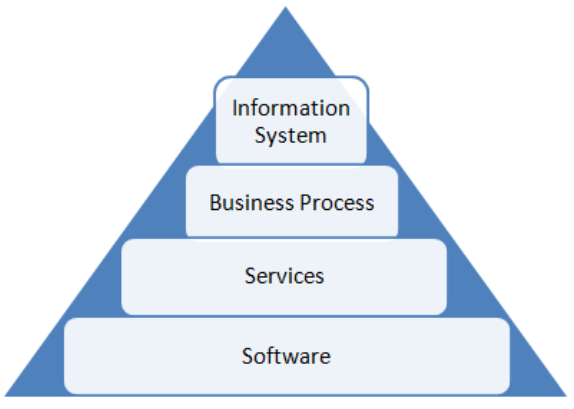

Fig. 3: The agile metric levels

In the following we present the set of level we have chosen as the first dimension and the different metric on which our model is based in the second dimension.

\section{A. Levels}

We propose 4 levels (Table 1):

- Information System (IS): This level includes the entire set of business management tools for information system.

- Business Process (BP): This level represents all possible trade flows and business workflows.

- Services (SV): For this level, it arises in a service oriented architecture (SOA) that contains a set of services that can be used independently.

- Software (SW): The software level is controlled by a set of development rules.

\section{B. Metrics}

The columns of our matrix (Table 1) represent the axes of metrics which was collected from our definition of agility:

- Appropriation Process (AP): It represents the flexibility desired in the system to monitor changes in the environment. This translates its inner ability to adapt appropriate behavior in new situations without seeing the need to introduce outside interventions.

- Adapting to Changes (AC): It presents all the operations to be set up by the company using its resources to adapt to external changes.

- Reduce Response Time (T): For being agile, you have to successfully reduce the response time. Hence, you must decrease the customer wait time to access services.

- Continue to Achieve the Objectives (OBJ): The strong feature of agility is the ability to continuously achieve the objectives despite environmental perturbations.

- Human Resources involvement (HR): The agile method is a user-centered approach. The human resources involvement should be considered throughout the product cycle level. 


\begin{tabular}{|c|c|c|c|c|c|}
\hline Metric & AP & AC & T & OBJ & HR \\
\hline & & & {$[38]$} & & \\
& {$[37]$} & {$[37]$} & {$[41]$} & {$[37]$} & {$[38]$} \\
IS & {$[41]$} & {$[38]$} & {$[45]$} & {$[41]$} & {$[37]$} \\
\hline & & {$[36]$} & & {$[38]$} & \\
& {$[36]$} & {$[8]$} & {$[38]$} & {$[34]$} & {$[37]$} \\
BP & {$[34][8]$} & {$[39]$} & {$[45]$} & {$[42]$} & {$[43]$} \\
\hline & & & & & {$[7]$} \\
& {$[7]$} & {$[8]$} & {$[38]$} & & {$[47]$} \\
& {$[39]$} & {$[47]$} & {$[40]$} & {$[8]$} & {$[48]$} \\
SV & {$[49]$} & {$[49]$} & {$[51]$} & {$[44]$} & {$[50]$} \\
\hline & {$[7]$} & & & & \\
& {$[39]$} & {$[8][7]$} & & {$[7]$} & {$[7]$} \\
& {$[49]$} & {$[47]$} & {$[7]$} & {$[39]$} & {$[47]$} \\
SW & {$[8]$} & {$[49]$} & {$[46]$} & {$[44]$} & {$[50]$} \\
\hline
\end{tabular}

TABLE I: Matrix of the proposed model

\section{Discussion}

Our model is inspired from the metrics proposed in the literature. Researchers took several directions. We find those who are basically interested in metrics related to the software part of the project. It proposes coding metrics and a set of unit testing [8] and profiling [46]. In terms of human resources management, we can talk about Scrum [7] a development team management methodology. It provides a set of practices based on sprints to regularize teamwork in software development. To continue to meet the objectives in line with customer requirements.

Other researches tries to go farther metric treatment in the higher layers to see the information system behavior. In this case, Yi Hong [37] provides a conceptual model of agility that focuses on the information system level. He proposes in the cooperation in terms of involvement of human resources, either in information systems and business process to make the integration process in the first agility plan. He also evokes the concept of flexibility and reactivity. In the same cluster, we find Couto [38] which is interested to information systems as well as processes. he deals with a new dimension of agility that is the reduction of response time. He proposes to provide a rapid evolution and integrate the concept of human resource management. Therefore, other researchers evoke the agility of information systems but only in an abstract way about the turbulence of the environment [41].

The third stream is to combine management methods with development methodologies as the case of J Erickson [39] that deals with metrics related to Extreme Programming in terms of agile modeling AM [36]. In the same, Giulio Concas in his book "Agile Processes in Software Engineering and Extreme Programming" combines metrics related to the team and the user through the agile methods on the one hand and on the other hand the quality of the developed code.

This proposed model uses a set of existing metrics in different contexts in order to bring the information system in its entirety from the software layer to the high-level layer to a level of agility.

\section{CONClusion}

Agility is a wide area. It remains an open subject and still attracting researchers and professionals. The researches consist of many concepts of agility. However, the high-level works are rare compared to other practices found in software development. The purpose of our model is to evaluate agility at several levels from software layer to the information system layer. This proposed model shows that the strength of a company depends on its ability to provide flexible applications by ensuring source code optimization during development. Furthermore, assessment of agility must exist with high level vision, by controlling the quality of services to adapt the environmental changes. Moreover, any change should not affect productivity. It is necessary to meet the objectives continuously, despite the turbulence with reducing the time of service access. In this step, the customer involvement plays a vital role to ensure the information system agility. Indeed, the feedback received by the customer helps to measure the satisfaction and control the quality of services.

The model we proposed is partially validated. It provides a first phase of an implementation agility. The next step is to see the evolution of these metrics. The observation from the behavior of these metrics allows to make decisions for their evolution.

Finally, we expect that this work can serve to motivate further work to develop other frameworks to evaluate agility of information system. Indeed, it is a huge domain and it deserves to be more developed to achieve agility specially in the information system. The literature contains a set of metrics to reflect the agility of information systems. However, what it lacks is an organization of these metrics. Then, we will propose an effective model, capable to measure the agility and thereafter to control it.

\section{REFERENCES}

[1] The standish group chao report 2012, The Year of the Executive Sponsor (https://cs.calvin.edu/)

[2] Sridhar Nerur, RadhaKanta Mahapatra and George Mangalaraj-2005 Challenges of Migrating "Agile Methodologies"

[3] Michael D. Hartline and O. C. Ferrell Journal of Marketing, The Management of Customer-Contact Service Employees: An Empirical Investigation

Vol. 60, No. 4 (Oct., 1996), pp. 52-70

[4] David E. Culler,Jaswinder Pal Singh,Anoop Gupta, "Parallel Computer Architecture: A Hardware/software Approach"

[5] Ismail H, Arokiam I, Reid J, Poolton J, Tey VS (2007), Agility Capability Indicators for Product Flexibility Assessment. International Journal of Agile Manufacturing 10: 13-28.

[6] Cockburn and Highsmith, Agile Software development Ecosystems

[7] Ken Schwaber, Best practices: Agile project management with scrum

[8] Kent Beck, Extreme Programming Explained: Embrace Change

[9] Alliance agile (http://www.agilealliance.com/)

[10] Manifesto (http://www.agilemanifesto.org/)

[11] Kidd P T (1994), Agile Manufacturing. Forging New Frontiers. AddisonWesley series in Manufacturing Systems

[12] Goldman S L, Nagel R N and Preiss K (1994), Agile Competitors and Virtual Organizations: Strategies for Enriching the Customer. Van Nostrand Reinhold, London.

[13] Gunasekaran A (1998), Agile Manufacturing: Enablers and an Implementation Framework. International Journal of Production Research 36: 1223-1247. 
[14] Ren J, Yusuf YY, Burns ND (2000), A Prototype of Measurement System for Agile Enterprise. Quality Management \& Technology 5: 30416.

[15] A-review-on-measurement-of-agility-2169-0316.1000121

[16] N. E. Shaw, T. F. Burgessa, C. de Mattosb, L. Z. Stecc, (2005) Supply chain agility: the influence of industry culture on asset capabilities within capital intensive industries. International Journal of Production Research, 43(16), 3497-3516

[17] 9th Annual state of agile survey (http://stateofagile.versionone.com/)

[18] Jean-Louis Le Moigne and Edgar H. Sibley, Information - Organization - Decision: Some Strange Loops

[19] Goepp V.2003, Contribution à la définition de processus contigent en développement de systèmes d'information

[20] Eynard, B., Gallet, T., Nowak, P. et Roucoules, L. (2004). UML based specifications of PDM product structure and workflow. Computers in Industry

[21] Panorama Consulting Solutions Research Report (2015) (PanoramaConsulting.com)

[22] Henderson, J C; Venkatraman, Strategic alignment: Leveraging information technology for transforming organizations, H. IBM Systems Journal38.2/3 (1999): 472-484.

[23] Paviot, T. (2010), Méthodologie de résolution des problèmes d'interopérabilité dans le domaine du PLM.

[24] John Graybeala, Anthony W. Isenorb, Carlos Ruedaa, Semantic mediation of vocabularies for ocean observing systems

[25] Karine Mordal-Manet and Nicolas Anquetil and Jannik Laval and Alexander Serebrenik and Bogdan Vasilescu and Stéphane Ducasse. Software quality metrics aggregation in industry. In Journal of Software: Evolution and Process, Special Issue: Software Maintenance and Reengineering (CSMR 2011), 25 (10): 1117-1135, 2013.

[26] M. Armbrust, A. Fox, R. Griffith, A. D. Joseph, R. H. Katz, A Konwinski, G. Lee, D. A. Patterson, A. Rabkin, I. Stoica, and M. Zaharia, "A View of Cloud Computing," Communications of the ACM, vol. 53, no. 4 , pp. $50-58$.

[27] Jörg Lenhard,Portability of Process-Aware and Service-Oriented Software Evidence and Metrics-University Bamberg

[28] Jackson M, Johansson C (2003) Agility Analysis from a Production System Perspective. Integrated Manufacturing Systems 14: 482-488.

[29] Van Hoek RI (2001), The Rediscovery Of Postponement A Literature Review And Directions For Research. Journal of Operations Management 19: $161-184$

[30] Bohdana Sherehiy, Waldemar Karwowski, John K Layer (2007), A review of enterprise agility: Concepts, frameworks, and attributes. Int J Ind Ergonom 37: 445-460.

[31] Ren J, Yusuf YY, Burns ND (2000) A Prototype of Measurement System for Agile Enterprise. Quality Management \& Technology 5: 304-16

[32] Tsour veloudis NC, Valavanis KP (2002) On the Measurement of Enterprise Agility. J Intell Robot Syst 33: 329-342

[33] YANG Shui-li, LI Tao-fen (2002), Agility Evaluation of Mass Customization Product Manufacturing. Journal of Materials processing Technology 41: 166

[34] Arteta BM, Giachetti RE (2004), A measure of agility as the complexity of the enterprise system. Robotics and Computer- Integrated Manufacturing 20: 495- 503.

[35] Yauch CA (2011) Measuring agility as a performance outcome, Journal of Manufacturing Technology Management 22: 384-404.

[36] S Ambler ( 2002), Agile modeling: effective practices for extreme programming and the unified process

[37] Yi-Hong Tseng, Ching-Torng Lin, Enhancing enterprise agility by deploying agile drivers, capabilities and providers

[38] ES Couto, MFC Lopes, RD Sousa, Can ISIT Governance Contribute for Business Agility?

Conference on ENTERprise Information Systems/International Conference on Project MANagement/Conference on Health and Social Care Information Systems and Technologies, CENTERIS/ProjMAN / HCist 2015 October 7-9, 2015

[39] J. Erickson, K. Lyytinen, and Keng Siau, "Agile Modeling, Agile Software Development, and Extreme Programming: The State of Research", Journal of Database Management, 16(4), 2005, pp. 88-100.

[40] K Channabasavaiah, K Holley, E Tuggle, Migrating to a service-oriented architecture -IBM DeveloperWorks, 2003 - 129.35.224.15
[41] R.D. Galliers, "Strategizing for Agility: Confronting Information Systems Inflexibility in Dynamic Environments", in Agile Information Systems: Conceptualization, Construction, and Management, K.C. Desouza, Editor. 2007. Butterworth-Heinemann: Amsterdam, Boston.

[42] TF Burgess - International Journal of Operations \& Production, Making the leap to agility: defining and achieving agile manufacturing through business process redesign and business network redesign

[43] M Hepp, F Leymann, J Domingue, Semantic business process management: A vision towards using semantic web services for business process management, 2005 - ieeexplore.ieee.org

[44] K Beck, Test-driven development: by example

[45] Morris A. Cohen, New Product Development: The Performance and Time-to-Market Trade off

[46] C Summers - US Patent 6,401,240, 2002 System and method for profiling code on symmetric multiprocessor architectures

[47] Danilo Sato, Alfredo Goldman, Fabio Kon, Tracking the Evolution of Object-Oriented Quality Metrics on Agile Projects

[48] J Highsmith, A Cockburn - Computer, 2001, Agile software development: The business of innovation - ieeexplore.ieee.org

[49] Giulio Concas, Ernesto Damiani, Marco Scotto, Giancarlo Succi, Agile Processes in Software Engineering and Extreme Programming 8th International Conference, XP 2007, Como, Italy, June 18-22, 2007 Proceedings

[50] M André, MG Baldoquín, ST Acuña - Information and Software Technology, 2011 - Elsevier

Formal model for assigning human resources to teams in software projects

[51] DA Menascé - IEEE Internet computing, 2004 - ieexplore.ieee.org Response-time analysis of composite Web services 